American Journal of Infectious Diseases 5 (3): 219-224, 2009

ISSN 1553-6203

(C) 2009 Science Publications

\title{
Mortality among HIV-Infected Patients in Resource Limited Settings: A Case Controlled Analysis of Inpatients at a Community Care Center
}

\author{
${ }^{1}$ Nirmala Rajagopalan, ${ }^{1}$ Joyce B. Suchitra, ${ }^{2}$ Anita Shet, ${ }^{3}$ Zafar K. Khan, \\ ${ }^{3}$ Julio Martin-Garcia, ${ }^{3}$ Michael R. Nonnemacher, ${ }^{3,4}$ Jeffrey M. Jacobson and ${ }^{3}$ Brian Wigdahl \\ ${ }^{1}$ Freedom Foundation, 180 Henur Cross, Bangalore, India \\ ${ }^{2}$ St. Johns Medical College and Hospital, Bangalore, India \\ ${ }^{3}$ Department of Microbiology and Immunology, Center for Molecular Virology and Neuroimmunology, \\ Center for Clinical and Translational Research, Center for International Medicine, \\ Institute for Molecular Medicine and Infectious Disease, USA \\ ${ }^{4}$ Department of Medicine, Division of Infectious Disease and HIV Medicine, \\ Drexel University College of Medicine, Philadelphia, PA 19102, USA
}

\begin{abstract}
Problem statement: Despite massive national efforts to scale up Antiretroviral Therapy (ART) access in India since 2004, the AIDS death rate was 17.2 per 100,000 persons during 20032005. In the era of HAART in resource poor settings, it is imperative to understand and address the causes of AIDS related mortality. This collaborative study aimed at defining the predictors of mortality among people living with HIV/AIDS (PLHA) admitted during 2003-2005 to the Freedom Foundation (FF) Care and Support facility, Bangalore, India. Approach: Fifty consecutively selected HIV-infected patients who died during the study period and $50 \mathrm{HIV}$-infected patients matched by age, gender, route of transmission, nutrition status and stage of disease who survived at least 12 months post-ART were included in this study. The impact on mortality by factors such as: Hemoglobin, CD4+T lymphocyte counts, weight loss and Opportunistic Infections (OIs) were studied. Statistical analyses were done by Chi-square, Fisher's Exact Test, Kaplan-Meier and multivariate logistic regression. Results: Recurrent diarrhea was a significant risk factor for mortality $(\mathrm{OR}=12.25, \mathrm{p}=0.004)$, followed by a diagnosis of pulmonary tuberculosis $(\mathrm{TB})$ at first admission $(\mathrm{OR}=4.86)$ while $\mathrm{TB}$ in general also negatively impacted survival $(\mathrm{p}=0.002)$. Though not statistically significant, Pneumocystis carinii pneumonia, Cryptococcal meningitis and Toxoplasmosis also negatively affected survival. Mortality was high among those not on HAART $(81 \%)$ while it was significantly reduced $(28 \%)$ among those on HAART $(\mathrm{p}<0.001)$. Patients who died had elevated liver enzymes $(\mathrm{p}=0.027)$ and significant weight loss $(\mathrm{p}=0.012)$. Mortality was high among patients irregular with their medical follow-up $(\mathrm{p}<0.001)$. Conclusion: Interventions that facilitate early OI diagnosis and treatment especially diarrhea and TB may reduce mortality in HIV. HAART alone without proper OI management and nutrition did not prevent mortality among PLHA. In resource poor settings, it becomes imperative to focus on low cost tools and increased capacity building along with regular clinical follow-up for diagnosis and early treatment of OIs. Further studies are warranted to explore benefits of initiating HAART earlier than currently recommended.
\end{abstract}

Key words: HIV-1, tuberculosis, opportunistic infections, antiretroviral therapy, diarrhea

\section{INTRODUCTION}

According to India's National Family Health Survey (NFHS-3), the prevalence of HIV in the country is now $0.3 \%$. Even with this reduced prevalence, India would still contribute to $30 \%$ of the HIV epidemic in $\mathrm{Asia}^{[1]}$. The national government is engaged in addressing the devastating HIV/AIDS epidemic utilizing several interventions, including free access to antiretroviral therapy launched in $2004^{[2]}$. Although increased access to treatment is likely to reduce mortality among HIV-infected individuals, there are studies in India that show that AIDS-related deaths is still about $9.73 \%$ in the present HAART era ${ }^{[3]}$. Under

Corresponding Author: Nirmala Rajagopalan, Senior Physician and Project Associate Freedom Foundation, 180 Hennur Cross, Bangalore, -560043 India Tel: 080-25435231/32 Fax: 080-25437496 
the prevailing conditions, it is important for clinicians, epidemiologists and policy makers to understand predictors of mortality in these individuals in order to formulate adjunct measures to prolong disease-free survival among HIV-infected individuals. The study described herein aimed to examine factors that predicted death among inpatients in the clinical setting of guidelines-based HAART access.

\section{MATERIALS AND METHODS}

The study was conducted at a community care center run by Freedom Foundation, an Indian nongovernmental organization based in Bangalore, India. Bangalore, the capital city of the high-HIV-prevalence State of Karnataka, is also geographically located close to the neighboring high-prevalence States of Tamil Nadu and Andhra Pradesh. This location has ensured adequate diversity of the inpatient population being seen at this care facility. HIV-infected individuals admitted to the inpatient facility between August 2004 and April 2006 was included in the analysis. HIV infection was confirmed in all subjects by three serial rapid HIV antibody tests ${ }^{[4]}$. Other clinical tests performed included CD4+T lymphocyte counts and basic biochemistry tests such as liver and renal function tests, hemoglobin levels and total and differential white blood cell counts. All patients were prescribed cotrimoxazole prophylaxis based on WHO guidelines.

Between August 2004 and April 2006, there were 1,096 patients who were newly registered at the center and received medical care as either in-patients or at the out-patient clinic; 591 previously seen patients were readmitted. The primary mode of infection among new patients was via unprotected heterosexual intercourse (91\%). A retrospective case record analysis was conducted to assess clinical and laboratory findings. All patients being admitted to the in-patient care facility for the first time were screened for inclusion in the analysis. Patients were divided into 2 groups; non-survivors $(n=50)$ included those who had expired during the study period within 12 months of being admitted to the care facility and survivors $(n=50)$ included those admitted to the care facility who survived beyond 12 months. Patients were matched for age and gender, transmission risk factors, nutrition status (weight and hemoglobin levels) and immunological status (CD4+T lymphocyte counts). Only those individuals with CD4+T lymphocyte counts $<200$ cells $\mathrm{mm}^{-3}$ or those with WHO staging 3 and CD $4<350$ or WHO stage 4 were included. The first opportunistic infection presenting at the time of and subsequent to admission was considered. Multiple logistic regression analysis was performed to assess the role of risk factors, which led to early mortality. Chi-square and Fisher exact tests were used to assess significant associations between opportunistic infections and early mortality. For data analysis, SPSS version 14.0 (SPSS Inc., Chicago, IL, USA) was used. All statistical tests were two-sided and $\mathrm{p}<0.05$ was considered statistically significant.

\section{RESULTS}

A comparison of socio-demographic and clinical factors between survivors and non-survivors presented in Table 1 showed similarity between the two groups. The male-female ratio between survivors and nonsurvivors were equal. Mean age among survivors was 32.32 years and among non-survivors was 34.70 years. Contact with multiple sexual partners was present in 60 and $52 \%$ of both groups respectively and the mean age at first sexual intercourse was approximately 20 years in both groups. There was no significant difference in the weight (mean weight was $46 \mathrm{~kg}+8.9$ ) or hemoglobin $(10.2 \%+2.1)$ of patients in the two groups at the time of first admission.

At time of first admission, among the total of 100 patients included in the study, 39\% were diagnosed with oral candidiasis, $38 \%$ with tuberculosis disease,

Table 1: Comparison of socio-demographic and clinical factors between survivors and non-survivors

\begin{tabular}{|c|c|c|c|}
\hline & $\begin{array}{l}\text { Survivors } \\
(\mathrm{n}=50)\end{array}$ & $\begin{array}{l}\text { Non-survivors } \\
(\mathrm{n}=50)\end{array}$ & $\begin{array}{l}\text { Significance } \\
\text { (p-value) }\end{array}$ \\
\hline \multicolumn{4}{|l|}{ Gender } \\
\hline Male & $38(76 \%)$ & $38(76 \%)$ & $>0.05$ \\
\hline Female & $12(24 \%)$ & $12(24 \%)$ & \\
\hline \multicolumn{4}{|l|}{ Education } \\
\hline Illiterate & $13(26.0 \%)$ & $7(14.0 \%)$ & 0.299 \\
\hline Primary and middle & $17(34.0 \%$ & $17(34.0 \%$ & $>0.05$ \\
\hline High school & $14(28.0 \%)$ & $22(44.0 \%)$ & 0.096 \\
\hline Graduate & $6(12.0 \%)$ & $2(4.0 \%)$ & 0.259 \\
\hline Not available & & $2(4.0 \%)$ & 0.495 \\
\hline \multicolumn{4}{|l|}{ Occupation } \\
\hline Agriculture & $8(16.0 \%)$ & $2(4.0 \%)$ & 0.046 \\
\hline Daily wage & $25(50 \%)$ & $24(48 \%)$ & 0.841 \\
\hline House wife & $5(10.0 \%)$ & $9(18.0 \%)$ & 0.249 \\
\hline $\begin{array}{l}\text { Others (salaried } \\
\text { workers, petty } \\
\text { business) }\end{array}$ & $12(24.0 \%)$ & $15(30.0 \%)$ & 0.362 \\
\hline \multicolumn{4}{|l|}{ Region } \\
\hline Urban & $13(26 \%)$ & $25(50 \%)$ & 0.013 \\
\hline Rural & $37(74 \%)$ & $25(50 \%)$ & \\
\hline $\begin{array}{l}\text { Multiple sexual } \\
\text { Partners }\end{array}$ & $30(60 \%)$ & $26(52 \%)$ & 0.400 \\
\hline $\begin{array}{l}\text { Mean CD4- } \\
\text { Tlymphocyte } \\
\text { count (cell } \mathrm{mm}^{-3} \text { ) }\end{array}$ & $99.80( \pm 69.81)$ & $81.95( \pm 76.59)$ & 0.100 \\
\hline $\begin{array}{l}\text { mean hemoglobin } \\
\left(\mathrm{gm} \mathrm{dL}^{-1}\right)\end{array}$ & $10.54( \pm 1.89)$ & $97.75( \pm 9.19)$ & 0.090 \\
\hline $\begin{array}{l}\text { Mean baseline } \\
\text { weight }(\mathrm{kg})\end{array}$ & $46.76( \pm 8.68)$ & $45.29( \pm 9.19)$ & 0.400 \\
\hline
\end{tabular}


Am. J. Infect. Dis., 5 (3): 219-224, 2009

Table 2: Opportunistic infections at first admission and mortality multivariate regression

\begin{tabular}{|c|c|c|c|c|}
\hline Factors & $\begin{array}{l}\text { No. of } \\
\text { survivors } \\
(\mathrm{n}=50)\end{array}$ & $\begin{array}{l}\text { No. of non- } \\
\text { survivors } \\
(\mathrm{n}=50)\end{array}$ & $\mathrm{p}$-value & $\begin{array}{l}\text { Adjusted } \\
\text { odds ratio }\end{array}$ \\
\hline $\begin{array}{l}\text { Pulmonary } \\
\text { tuberculosis }\end{array}$ & 7 & 19 & $0.019^{*}$ & 4.86 \\
\hline $\begin{array}{l}\text { Tubercular } \\
\text { lymphadenitis }\end{array}$ & 1 & 3 & 0.239 & 4.50 \\
\hline $\begin{array}{l}\text { Abdominal } \\
\text { tuberculosis }\end{array}$ & 2 & 3 & 0.399 & 2.49 \\
\hline $\begin{array}{l}\text { Tuberculous } \\
\text { Meningitis }\end{array}$ & 1 & 2 & 0.494 & 2.54 \\
\hline $\begin{array}{l}\text { Presence any of } \\
\text { tuberculosis infection }\end{array}$ & 11 & 27 & $0.002 *$ & 4.16 \\
\hline $\begin{array}{l}\text { Pnecumocystis } \\
\text { jiroveci pneumonia }\end{array}$ & 1 & 4 & 0.279 & 4.09 \\
\hline $\begin{array}{l}\text { Cryptococcal } \\
\text { Meningitis }\end{array}$ & 3 & 4 & 0.572 & 1.76 \\
\hline Persistent diatthoca & 1 & 10 & $0.004 *$ & 12.25 \\
\hline Toxoplasmosis & 1 & 1 & 0.504 & 1.72 \\
\hline $\begin{array}{l}\text { Cytomegalovirus } \\
\text { infection }\end{array}$ & 0 & 2 & 0.884 & 1.10 \\
\hline Oral candidiasis & 19 & 20 & 0.996 & 1.00 \\
\hline $\begin{array}{l}\text { Presumed bacterial } \\
\text { pneumonia }\end{array}$ & 11 & 3 & 0.731 & 0.55 \\
\hline
\end{tabular}

$28 \%$ with chronic diarrhea (diarrhea persisting more than 4 weeks $)^{[5]}, 7 \%$ with cryptococcal meningitis, 5\% with Pneumocystis jiroveci pneumonia (PCP) and 14\% with presumed bacterial pneumonia. Of the total number of patients with tuberculosis $(\mathrm{n}=38), 68.4 \%$ had pulmonary tuberculosis, $7.8 \%$ had tuberculous meningitis, $10.5 \%$ had tuberculous lymphadenitis and $13 \%$ had abdominal tuberculosis. Among the patients with diarrhea $(\mathrm{n}=28), 22 \%$ required frequent admissions. Disseminated cytomegalovirus infection was observed in $4 \%$ of non-survivors. The mean CD4 count among survivors at time of first admission was $99.8+69.81$ and among non-survivors was $81.95+76.59$ (the difference was not statistically significant).

The multivariate logistic regression analysis (Table 2) showed that chronic diarrhea was a highly significant risk factor for mortality $(\mathrm{OR}=12.25$, $\mathrm{p}=0.004)$. The other infection that negatively affected survival was tuberculosis (4.16 times risk of mortality) $(\mathrm{p}=0.002,95 \% \mathrm{CI}: 1.74-9.93)$. Although statistical significance was not noted, Cryptococcal meningitis $(\mathrm{OR}=1.76, \mathrm{p}=0.57), \mathrm{PCP},(\mathrm{OR}=4.09, \mathrm{p}=0.27)$ and toxoplasmosis $(\mathrm{OR}=1.72, \mathrm{p}=0.5)$ exhibited a negative trend on patient survival. The causes of mortality in this cohort are shown in Table 3. Non-survivors were also more likely to have elevated liver enzymes $12 \%$ $(\mathrm{p}=0.027)$ and accelerated weight loss $(\mathrm{p}=0.012)$. Regular clinical follow-up had a positive impact on survival. Among survivors, $86 \%$ came for regular medical consultation, compared to $44 \%$ among those who died (regular follow-up was defined as people
Table 3: Cause of death seen among patients included in the study

\begin{tabular}{ll}
\hline Chronic diarrhea & $3(6 \%)$ \\
Tuberculosis & $22(44 \%)$ \\
Cytomegalovirus infection & $2(4 \%)$ \\
Cryptococcal meningitis & $5(10 \%)$ \\
Renal failure & $1(2 \%)$ \\
Hepatic failure & $2(4 \%)$ \\
Acute pancreatitis & $1(2 \%)$ \\
AIDS related wasting and general debility & $8(16 \%)$ \\
Pncumocystis & $1(2 \%)$ \\
Steven jhonsons & $1(2 \%)$ \\
syndrome with nevirapine & \\
\hline
\end{tabular}

living with HIV/AIDS, PLHA, visiting the clinic once in three months and/or as advised by the doctor), $81 \%$ of those not on HAART died during the study period while among those on HAART, 28\% had died which was a significant difference $(\mathrm{p}<0.001)$.

\section{DISCUSSION}

Studies from affluent settings show that in the era of HAART, the causes of mortality in people infected with HIV are not all due to AIDS-related events ${ }^{[6,7]}$. However, in resource poor settings, opportunistic infections still contribute to a large number of AIDSrelated deaths and this may be accelerated in those not taking prophylaxis and those unable to access medical care $^{[8]}$.

The study reported herein study demonstrated that chronic diarrhea was associated with not only frequent hospitalization but also a higher risk of mortality. Most studies from resource poor settings have focused on $\mathrm{TB}^{[9]}$ while studies that focused on diarrhea have mainly looked at the etiology ${ }^{[10-12]}$. However, this study has been able to demonstrate the importance of being able to diagnose and effectively treat diarrhea in order to decrease morbidity and mortality among PLHA. This also implies that there is still a need to educate PLHA regarding prevention of diarrhea. In India, the tendency to utilize over-the-counter medications to treat diarrhea rather than seek medical care remains a highly prevalent practice among PLHA. A prospective study that examines the outcome of chronic diarrhea among PLHA in resource poor settings is warranted.

TB/HIV co-infection still remains a big challenge, with TB accounting for nearly 13\% of AIDS deaths worldwide ${ }^{[13]}$. Studies from African settings have also shown the relationship between tuberculosis/HIV coinfection and increased mortality ${ }^{[14,15]}$. Consistent with these observations, studies performed in India have reported over 50\% TB/HIV co-infection in their study cohorts with higher mortality in those individuals with TB/HIV co-infection ${ }^{[16-21]}$. Increased incidence of postpartum TB and associated maternal deaths have also 
been reported among HIV-infected women from antenatal clinics ${ }^{[22]}$. Tuberculosis was found to be the most common "AIDS-defining" opportunistic infection among a cohort of HIV-infected individuals in south India, accounting for nearly $50 \%$ of all $\mathrm{OIs}^{[23]}$. Although mortality associated with TB has remained steady over the years, combined mortality due to HIV/TB coinfection has increased dramatically ${ }^{[24]}$. Tuberculosis is a leading cause of death for HIVinfected individuals, accounting for up to $11 \%$ of AIDS-related mortality worldwide ${ }^{[25]}$. A recently published longitudinal study conducted in Uganda indicated that cumulative mortality among HIVinfected patients diagnosed with TB at baseline or follow-up was higher than those HIV-infected without $\mathrm{TB}^{[28]}$. The study also demonstrated that $\mathrm{TB}$ incidence declined dramatically after subjects were treated with HAART for 6 months. The ongoing high mortality associated with TB is a concern for patients on HAART in areas of high TB prevalence. Much of this mortality may be linked to the late stage at which many subjects in this study initiated HAART.

It is conceivable that HAART has the potential to be effective in preventing both chronic diarrhea and also TB in individuals if therapy had been started at an earlier time point when the CD4+T lymphocyte counts were higher. Current WHO and Indian National Guidelines recommend initiation of HAART at CD4+T lymphocyte counts of $<200$ cells $\mathrm{mm}^{-3}$ or for patients with WHO disease staging III and $\mathrm{IV}^{[26,27]}$. However, earlier initiation of HAART when CD4+T lymphocyte counts are between 200 and 350 cells $\mathrm{mm}^{-3}$, along with improved strategies to diagnose and treat underlying opportunistic infections and extensive adherence counseling may play a role in decreasing mortality by preventing the occurrence of opportunistic infections, especially tuberculosis ${ }^{[31]}$. Prospective research studies exploring this approach are needed in order to weigh the risks and benefits of earlier initiation of HAART.

Major opportunistic infections such as cryptococcal infections, toxoplasmosis and PCP continue to contribute to AIDS-related mortality despite the increased access and utilization of antiretroviral therapy ${ }^{[28-30]}$. Many of those who died also had accelerated weight loss $(26 \%)$ and low hemoglobin levels $(36 \%)$, confirming the strong relationships between these markers and mortality ${ }^{[31-34]}$. Weight loss as a prognostic marker of advanced HIV infection has been well studied ${ }^{[35]}$. Poor nutritional intake, metabolic effects of drugs, opportunistic infections and increased catabolism are likely contributing factors ${ }^{[36]}$. Several studies have shown that falling hemoglobin is significantly associated with increased mortality independent of CD4+T lymphocyte counts in patients with HIV infection ${ }^{[37,38]}$.

The studies reported herein are limited by the small sample size as well as the retrospective nature of the study. These limitations not withstanding, the findings of this study have practical implications for managing HIV-infected patients in India.

\section{CONCLUSION}

The strong association between the presence of chronic diarrhea and early mortality indicates the need for improved diagnostic and preventive methods and aggressive treatment approaches. The same applies to HIV/TB co-infections. The study highlights the importance of having a close linkage between OI management and HAART care services and that this is fundamental for the successful management of HIV/AIDS. For patients with advanced disease, enhanced counseling focusing on adherence to care and frequent follow-up clinic visits could allow for the prevention and early diagnosis of opportunistic infections.

\section{ACKNOWLEGDEMENT}

These studies were funded in part by the Public Health Service, National Institutes of Health through grants (B. Wigdahl, Principal Investigator) from the National Institute of Neurological Disorders and Stroke (NS32092 and NS46263) and the National Institute of Drug Abuse (DA19807).

\section{REFERENCES}

1. NFHS-3 Sheds New Light on HIV Prevalence. http://www.nfhsindia.org/NFHS-

3\%20Data/Press\%20Briefing\%20Kit/HIV\%20AID S.pdf

2. National AIDS Control Program, 2006. National AIDS Control Program Phase III (2006-201): Strategy and Implementation Plan: Ministry of Health and Family Welfare, Government of India. http://www.nacoonline.org/upload/Publication/Stra tegy\%20and\%20Implementation\%20Plan\%20$\% 20$ NACO $\% 20$ Programme $\% 20$ Phase $\% 20$ III\%20( 2006-2011)\%202006.pdf

3. Teja, V.D., T. Sudha and V. Lakshmi, 2007. Causes and pattern of mortality in HIV-infected, hospitalized patients in a tertiary care hospital: A fourteen year study. Indian J. Med. Sci., 61: 555-556. http://www.ncbi.nlm.nih.gov/pubmed/17932446 
4. Guidelines on HIV Testing, 2007. National AIDS Control Organization (Ministry of Health and Family Welfare, Government of India). http://www.nacoonline.org/upload/Final\%20Public ations/Blood\%20Safety/GUILDELINES\%20FOR \%20HIV\%20TESTING.pdf

5. Thomas, P.D., A. Forbes, J. Green, P. Howdle, R. Long, R. Long and R. Playford et al., 2003. Guidelines for the Investigation of Chronic Diarrhea. British Society of Gastroenterology, 52: v1-v5. http://www.pubmedcentral.nih.gov/articlerender.fc gi?artid $=1867765$

6. Bonnet, F., P. Morlat, G. Chene, P. Mercie, D. Neau, I. Chossat, M. Decoin, F. Djossou, J. Beylot and F. Dabis, 2002. Causes of death among HIVinfected patients in the era of highly active antiretroviral therapy, Bordeaux, France, 19981999. HIV. Med., 3: 195-199. http://direct.bl.uk/bld/PlaceOrder.do?UIN=116655 044\&ETOC $=$ RN\&from $=$ searchengine

7. Bonnet, F., C. Lewden, T. May, L. Heripret, E. Jougla and S. Bevilacqua et al., 2005. Opportunistic infections as causes of death in HIV-infected patients in the HAART era in France. Scand J. Infect. $\quad$ Dis., 37: 482-487. http://cat.inist.fr/?aModele $=$ afficheN\&cpsidt $=16935816$

8. Mzileni, M.O., M.B. Longo and T.J. Chephe, 2008. Mortality and causes of death in HIV-positive patients receiving antiretroviral therapy at Tshepang Clinic in Doctor George Mukhari Hospital. Pol. Arch. Med. Wewn., 118: 548-545. http://www.ncbi.nlm.nih.gov/pubmed/19112815

9. Gupta, S., S. Narang, V. Nunavath and S. Singh, 2008. Chronic diarrhoea in HIV patients: Prevalence of coccidian parasites. Indian J. Med. Microbiol., $\quad$ 26: 172-175. http://medind.nic.in/iau/t08/i2/iaut08i2p172.pdf

10. Prasad, K.N., V.L. Nag, T.N. Dhole and A. Ayyagari, 2000. Identification of enteric pathogens in HIVpositive patients with diarrhoea in northern India. J. Health Populat. Nutr., 18: 23-26. http://www.ncbi.nlm.nih.gov/pubmed/11014766

11. Rao Ajjampur, S.S., J.R. Asirvatham, D. Muthusamy and B.P. Gladstone et al., 2007. Clinical features and risk factors associated with cryptosporidiosis in HIV infected adults in India. Indian J. Med. Res., $\quad$ 126: 553-557. http://www.pubmedcentral.nih.gov/articlerender.fc gi?artid $=2673507$

12. Colebunders, R. and M.L. Lambert, 2002. Management of co-infection with HIV and TB. BMJ., 324: 802-803.

http://bmj.bmjjournals.com/cgi/content/full/324/73 $41 / 802$
13. Ackah, A.N., D. Coulibaly, H. Digbeu, K. Diallo and K.M. Vetter et al., 1995. Response to treatment, mortality and CD4 lymphocyte counts in HIV-infected persons with tuberculosis in Abidjan, Cote d'Ivoire. Lancet, 345: 607-610. http://www.ncbi.nlm.nih.gov/pubmed/7898177

14. Whalen, C.C., P. Nsubuga, A. Okwera, J.L. Johnson and D.L. Hom et al., 2000. Impact of pulmonary tuberculosis on survival of HIV-infected adults: A prospective epidemiologic study in Uganda. AIDS., $\quad 14:$ 1219-1228. http://www.ncbi.nlm.nih.gov/pubmed/10894287

15. Hira, S.K., H.J. Shroff, D.N. Lanjewar, Y.N. Dholkia, V.P. Bhatia and H.L. Dupont, 2003. The natural history of human immunodeficiency virus infection among adults in Mumbai. Natl. Med. J. India, 16: 126-131.

http://direct.bl.uk/bld/PlaceOrder.do?UIN=142526 $734 \&$ ETOC $=$ RN\& from $=$ searchengine

16. Kumarasamy, N., 2005. Can we reduce morbidity and mortality due to HIV and stop transmission in India? Indian J. Med. Res., 122: 461-463. http://www.ncbi.nlm.nih.gov/pubmed/16517994

17. Maniar, J.K., R.R. Kamath, S. Mandalia, K. Shah and A. Maniar, 2006. HIV and tuberculosis: Partners in crime. Indian J. Dermatol. Venereol. Leprol., $\quad$ 72: 276-282. http://www.ncbi.nlm.nih.gov/pubmed/16880573

18. Rupali, P., O.C. Abraham, A. Zachariah, S. Subramanian and D. Mathai, 2003. Aetiology of prolonged fever in antiretroviral-naive human immunodeficiency virus-infected adults. Natl. Med. J. India, 16: 193-199. http://www.ncbi.nlm.nih.gov/pubmed/14606766

19. Sharma, S.K., T. Kadhiravan, A. Banga, T. Goyal, I. Bhatia and P.K. Saha, 2004. Spectrum of clinical disease in a series of 135 hospitalized HIV-infected patients from north India. BMC Infect. Dis., 4: 52. http://www.ncbi.nlm.nih.gov/pubmed/15555069

20. Sharma, S.K., A. Mohan and T. Kadhiravan, 2005. HIV-TB co-infection: Epidemiology, diagnosis and management. Indian J. Med. Res., 121: 550-567. http://www.ncbi.nlm.nih.gov/pubmed/15817963

21. Singh, A., I. Bairy and P.G. Shivananda, 2003. Spectrum of opportunistic infections in AIDS cases. Indian J. Med. Sci., 57: 16-21. http://www.ncbi.nlm.nih.gov/pubmed/14514281

22. Gupta, A., U. Nayak, M. Ram, R. Bhosale, S. Patil, A. Basavraj, A. Kakrani, S. Philip, D. Desai, J. Sastry and R.C. Bollinger, 2007. Postpartum tuberculosis incidence and mortality among HIVinfected women and their infants in Pune, India, 2002-2005. Clin. Infect. Dis., 45: 241-249. http://www.ncbi.nlm.nih.gov/pubmed/17578786 
23. Kumarasamy, N., S. Solomon, T.P. Flanigan, R. Hemalatha, S.P. Thyagarajan and K.H. Mayer, 2003. Natural history of human immunodeficiency virus disease in southern India. Clin. Infect. Dis., 36: 79-85.

http://www.ncbi.nlm.nih.gov/pubmed/12491206

24. Perneger, T.V., P. Sudre, J.D. Lundgren and B. Hirschel, 1995. Does the onset of tuberculosis in AIDS predict shorter survival? Results of a cohort study in 17 European countries over 13 years. AIDS in Europe Study Group. Br. Med. J., 311: 1468-1471. http://bmj.bmjjournals.com/cgi/content/abstract/31 1/7018/1468

25. Corbett, E.L., C.J. Watt, N. Walker, D. Maher, B.G. Williams, M.C. Raviglione and C. Dye, 2003. The growing burden of tuberculosis: Global trends and interactions with the HIV epidemic. Arch. Int. Med., 163: 1009-1021. http://www.ncbi.nlm.nih.gov/pubmed/12742798

26. Moore, D., C. Liechty, P. Ekwaru, W. Were, G. Mwima, P. Solberg, G. Rutherford and J. Mermin, 2007. Prevalence, incidence and mortality associated with tuberculosis in HIV-infected patients initiating antiretroviral therapy in rural Uganda. AIDS., 21: 713-719.

http://www.ncbi.nlm.nih.gov/pubmed/17413692

27. Organization, N.A.C., 2007. Antiretroviral therapy guidelines for HIV-infected adults and adolescents including post-exposure prophylaxis: Ministry of Helath and Family Welfare, Government of India. http://www.nacoonline.org/upload/Publication/Tre atment\%20Care\%20and\%20support/Antiretroviral $\% 20$ Therapy\%20Guidelines $\% 20$ for $\% 20 \mathrm{HIV}$ -

Infected $\% 20$ Adults $\% 20$ and $\% 20$ Adolescents $\% 20$ In cluding\%20Post-exposure.pdf

28. Organization, W.H., 2006. Antiretroviral Therapy for HIV Infection in Adults and Adolescents: Recommendations for a Public Approach Geneva. World Health Organization, Switzerland. http://www.who.int/hiv/pub/guidelines/artadultguid elines.pdf

29. AETC., 2007. AIDS Educational Training Center Clinical Manual: CD4 monitoring and Viral Load Testing. AETC National Resource Center. http://aidsetc.org/aidsetc?page=cm-107_cd4_monitor

30. Nissapatorn, V., C. Lee, K.F. Quek, C.L. Leong, R. Mahmud and K.A. Abdullah, 2004. Toxoplasmosis in HIV/AIDS patients: A current situation. Jap J. Infect. Dis., 57: 160-165. http://gateway.nlm.nih.gov/MeetingAbstracts/1022 76413.html
31. Schaars, C.F., G.A. Meintjes, C. Morroni, F.A. Post and G. Maartens, 2006. Outcome of AIDSassociated cryptococcal meningitis initially treated with $200 \mathrm{mg} /$ day or $400 \mathrm{mg} /$ day of fluconazole. BMC. Infect. Dis., 6: 118. http://www.ncbi.nlm.nih.gov/pubmed/16846523

32. Selik, R.M., J.M. Karon and J.W. Ward, 1997. Effect of the human immunodeficiency virus epidemic on mortality from opportunistic infections in the United States in 1993. J. Infect. Dis., 176: 632-636.

http://cat.inist.fr/?aModele $=$ afficheN\&cpsidt $=2823$ 284

33. Paton, N.I., S. Sangeetha, A. Earnest and R. Bellamy, 2006. The impact of malnutrition on survival and the CD4 count response in HIV-infected patients starting antiretroviral therapy. HIV. Med., 7: 323-330. http://www.ncbi.nlm.nih.gov/pubmed/16945078

34. Sullivan, P.S., D.L. Hanson, S.Y. Chu, J.L. Jones and J.W. Ward, 1998. Epidemiology of anemia in Human Immunodeficiency Virus (HIV)-infected persons: results from the multistate adult and adolescent spectrum of HIV disease surveillance project. Blood, 91: 301-308. http://bloodjournal.hematologylibrary.org/cgi/conte nt/full/91/1/301

35. Mangili, A., D.H. Murman, A.M. Zampini and C.A. Wanke, 2006. Nutrition and HIV infection: Review of weight loss and wasting in the era of highly active antiretroviral therapy from the nutrition for healthy living cohort. Clin. Infect. Dis., 42: 836-842.

http://www.ncbi.nlm.nih.gov/pubmed/16477562

36. Mwamburi, D.M., I.B. Wilson, D.L. Jacobson and D. Spiegelman et al., 2005. Understanding the role of HIV load in determining weight change in the era of highly active antiretroviral therapy. Clin. Infect. $\quad$ Dis., 40 167-173. http://www.ncbi.nlm.nih.gov/pubmed/15614708

37. Belperio, P.S. and D.C. Rhew, 2004. Prevalence and outcomes of anemia in individuals with human immunodeficiency virus: a systematic review of the literature. Am. J. Med., 116: 27S-43S. http://www.ncbi.nlm.nih.gov/pubmed/15050884

39. Shah, S., C.J. Smith, F. Lampe, M. Youle, M.A. Johnson, A.N. Phillips and C.A. Sabin, 2007. Haemoglobin and albumin as markers of HIV disease progression in the highly active antiretroviral therapy era: Relationships with gender. HIV Med., 8: 38-45. DOI:_10.1111/j.14681293.2007.00434.x 